Furthermore, univariate models showed that age $(p=0.738)$, disease duration $p=0.090$, previous DMARDs $(p=0.616)$, and HAQ $(p=0.674)$ and BASFI (scores $p=0.850$ ) were not statistically significant predictors of gastrointestinal infections. Conclusions: The incidence rate of gastrointestinal infections in SpA patients treated with anti-TNF drugs is not increased. Being female and having comorbidities are predictive factors of gastrointestinal infections.

Disclosure of Interest: None declared

DOI: 10.1136/annrheumdis-2017-eular.5936

\section{THU0367 THE INFLUENCES OF NON-STEROIDAL ANTI-INFLAMMATORY DRUGS ON SERUM VEGF AND BMP-2 LEVELS IN PATIENTS WITH AXIAL SPONDYLOARTHRITIS}

G. Gao, L. Lu, Z. Li, Y. Li. Rheumatology, the First Affiliated Hospital of Zhengzhou Unversity, Zhengzhou, China

Background: VEGF has been found abnormal in patients with SpA and related to disease activity $[1,2]$. BMP-2 has a function of promoting the osteophyte formation, and may be involved in the integration process of AS spine [3,4]. VEGF and BMP-2 interact with each other, participating in the formation of osteoblast [5]. COX-2 works together with the expressions of BMP2 and VEGF is an important factor of heterotopic ossification [6].

Objectives: To investigate the serum levels of VEGF and BMP-2 in axSPA treated with NSAIDs and their possible relationship with disease activity.

Methods: 120 patients with axSPA were randomized administered with imrecoxib or celecoxib respectively for 3 months. Serum VEGF and BMP-2 were detected. ESR, CRP, BASDAI, BASFI and SPARCC were measured.

Results: A statistically significant change was found in ESR, BASDAl, patients global assessment of disease activity, Schober test and SPARCC following treatment with imrecoxib or celecoxib $(P<0.05)$. There were no statistically significant differences between the two groups. $(P>0.05)$. There was statistically significant difference in serum VEGF levels before and after treatment $(240.89 \pm 17.68 \mathrm{pg} / \mathrm{ml}$ vs $187.00 \pm 11.42 \mathrm{pg} / \mathrm{ml}, \mathrm{P}<0.05)$, but no difference in BMP-2 $(231.74 \pm 104.44$ vs $226.80 \pm 116.26 \mathrm{pg} / \mathrm{ml}, P>0.05)$. A significant correlation was found between VEGF level and ESR, CRP, BASFI, tragus-up-wall distance and finger to floor distance, lumbar side flexion,Schober test and intermalleoar distance $(r=0.628$, $0.542,0.238,0.299,0.353,-0.369,-0.373,-0.359,-0.274, P<0.05)$. And the BMP-2 levels were correlated with CRP and lumbar side flexion $(r=0.213,-0.190$, $P<0.05)$. Serum VEGF levels were significantly increased in HLA-B27-positive patients than in HLA-B27-negative ones $(P<0.05)$.

Conclusions: NSAIDs can not only improve symptoms and function, but also reduce sacroilitis possibly by affecting the levels of VEGF and BMP. Imrecoxib and celecoxib have the same efficacy.The response to treatment was correlated with the expression of HLA-B27.

References:

[1] Appel H,Janssen L,Listing J,Heydrich R,Rudwaleit M,Sieper J.Serum levels of biomarkers of bone and cartilage destruction and new bone formation in different cohorts of patients with axial spondyloarthritis with and without tumor necrosis factor-alpha blocker treatment.Arthritis Res Ther;2008:10:R125.

[2] Liu KG,He QH,Tan JW,Liao GJ.Expression of TNF-alpha, VEGF, and MMP-3 mRNAs in synovial tissues and their roles in fibroblast-mediated osteogenesis in ankylosing spondylitis.Genet Mol Res;2015:14:6852-6858.

[3] Poddubnyy D,Conrad K,Haibel H,Syrbe U,Appel H,Braun J,et al. Elevated serum level of the vascular endothelial growth factor predicts radiographic spinal progression in patients with axial spondyloarthritis.Ann Rheum Dis;2014:73:2137-2143.

[4] Chen MH,Chen HA,Chen WS,Chen MH,Tsai CY,Chou CT.Upregulation of BMP-2 expression in peripheral blood mononuclear cells by proinflammatory cytokines and radiographic progression in ankylosing spondylitis.Mod Rheumatol;2015:25:913-918.

[5] Minamizaki T,Yoshiko Y,Kozai K,Aubin JE,Maeda N.EP2 and EP4 receptors differentially mediate MAPK pathways underlying anabolic actions of prostaglandin E2 on bone formation in rat calvaria cell cultures.Bone;2009:44:1177-1185.

[6] Pape HC,Marcucio R,Humphrey C,Colnot C,Knobe M,Harvey EJ.Traumainduced inflammation and fracture healing. J Orthop Trauma. 2010 2010-0901;24:522-5.

Acknowledgements: no.

Disclosure of Interest: None declared

DOI: 10.1136/annrheumdis-2017-eular.5582

\section{THU0368 CLINICAL AND IMAGING CHARACTERISTICS OF PATIENTS WITH AXIAL SPONDYLOARTHRITIS REPORTING FLARE SYMPTOMS IMMEDIATELY PRIOR TO NEXT DOSE IN ROUTINE TNFI THERAPY}

R. Ansell, H. Mathieson, M. Merashli, N. Busquets-Pérez, D. McGonagle, H. Marzo-Ortega. Nihr Lmbru, Leeds Teaching Hospitals Trust and LIRMM, University of Leeds, Leeds, United Kingdom

Background: Tumour necrosis factor inhibitors (TNFi) are highly efficacious in axial spondyloarthritis $(\mathrm{axSpA})$ with significant clinical responses mirrored in resolution of MRI determined bone marrow oedema (BMO) lesions representative of active inflammation in the sacroiliac joints (SIJ) and spine. However, symptom flare suggesting loss of response is common with many patients reporting deterioration days or weeks prior to the next dose. We hypothesised that intermittent suppression of inflammation with longer acting TNFis such as adalimumab or infliximab may be associated with a greater likelihood of recurrence of MRI determined BMO lesions than shorter acting agents such as etanercept.

Objectives: To explore the relationship between symptom flare immediately prior to next treatment dose and recurrence of MRI determined BMO lesions with different TNFi in axSpA.

Methods: Proof-of-concept, single centre study. Eligible participants were adults with axSpA established on adalimumab, etanercept or infliximab describing loss of response immediately prior to next treatment dose. Loss of response was defined as subjective "flare" or "wearing off" of drug effect before the expected duration of treatment effect. Participants attended at three points: Baseline: first day of treatment cycle (day of drug dose); Endpoint 1: 3-4 days after dose; and Endpoint 2: within 48 hours of next dose. ASDAS-CRP and whole spine and SIJ MR imaging utilising $3 T$ MRI scanner were performed at each visit. Images were scored according to the semi-quantitative Leeds MRI scoring system by two observers blinded to participant identity and date of scan.

Results: 38 participants ( 16 adalimumab; 12 etanercept; 10 infliximab) with a total 113 MRI scans were analysed. $71 \%(n=27)$ male; $60 \%(n=23)$ HLA-B27+ with no differences between the groups; $73.7 \%(n=28)$ fulfilled mNYC for AS; the remainder were classified as $\mathrm{nr}$-axSpA. $58 \%(\mathrm{n}=22)$ had at least 1 Grade $1 \mathrm{BMO}$ lesion at baseline with lesions more commonly seen with longer acting drugs (5/12 in etanercept group; $9 / 16$ in adalimumab group; $8 / 10$ in infliximab group) and $11(50 \%)$ had at least 1 Grade $\geq 2$ lesion (Table 2). There was a trend towards number and severity of BMO lesions fluctuating through the treatment cycle (Figure 1) mimicking subjective loss of response, also reflected on the ASDAS-CRP (Table 1) but this did not reach statistical significance.

Table 1. Median (range) ASDAS-CRP by drug and visit

\begin{tabular}{lccc}
\hline & Baseline & Endpoint 1 & Endpoint 2 \\
\hline Etanercept & $2.94(1.5-4.4)$ & $2.46(1.8-4.0)$ & $3.18(1.1-4.2)$ \\
Adalimumab & $2.97(1.7-5.5)$ & $2.17(1.0-7.9)$ & $2.79(1.4-5.3)$ \\
Infliximab & $3.3(3.0-4.7)$ & $2.93(1.0-4.5)$ & $3.31(2.8-4.8)$ \\
\hline
\end{tabular}

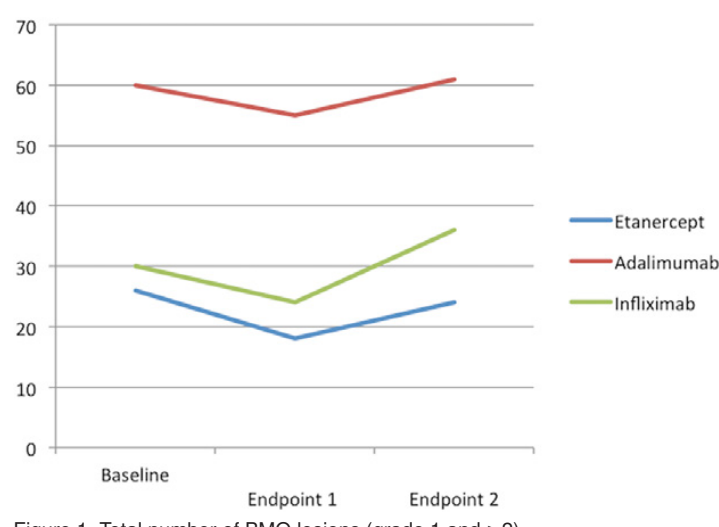

Figure 1. Total number of BMO lesions (grade 1 and $\geq 2$ ).

Conclusions: This small proof-of-concept study shows subtle fluctuations on $\mathrm{MRI}$ changes of BMO and ASDAS-CRP corresponding to time of subjective "flare" before next scheduled TNFi dose in subjects with axSpA. Although these changes may be more common with the longer acting TNFi our data are not confirmatory. Larger studies are required to explore this concept further as these observations are potentially relevant for disease progression since cycles of inflammation and its subsequent suppression could theoretically increase the risk of new bone formation.

Acknowledgements: This study was sponsored by Pfizer

Disclosure of Interest: R. Ansell Grant/research support from: Pfizer, H. Mathieson: None declared, M. Merashli: None declared, N. Busquets-Pérez: None declared, D. McGonagle Grant/research support from: Celgene, Janssen \& Pfizer, Consultant for: AbbVie, Celgene, Janssen, Novartis, UCB, Speakers bureau: Abbvie, Celgene, Janssen, UCB., H. Marzo-Ortega Grant/research support from: Janssen \& Pfizer., Consultant for: AbbVie, Celgene, Janssen, Novartis, UCB. S, Speakers bureau: Abbvie, Celgene, Janssen, UCB.

DOI: 10.1136/annrheumdis-2017-eular.6653 